\title{
Volver a donde nunca se estuvo. Pacto social, felicidad pública y educación en Chile (c.1810-c.2010)
}

\section{Back to where it was never. Social Pact, Public Happiness and Education in Chile (c.1810-c.2010)}

\author{
Pablo Toro Blanco ${ }^{1}$ \\ Universidad Alberto Hurtado (Chile)
}

Recibido: 22-05-17

Aprobado: 05-06-17

\section{Resumen}

El reciente malestar social que ha recorrido a Chile desde hace más de una década ha tenido como tema central la demanda por cambios educacionales que superen un sistema fundado prioritariamente en los mecanismos de mercado y el debilitamiento de la educación pública, herencias de la dictadura cívicomilitar encabezada por Augusto Pinochet (1973-1990). A partir de ese contexto, este artículo (con elementos de ensayo) se preocupa de presentar una selección de coyunturas históricas en las que se pone en diálogo a la educación con los fundamentos del pacto social y las cambiantes nociones acerca del bien social que apareja la educación.

Palabras-clave: educación chilena, pacto social, Estado Docente, Derecho a la Educación.

\footnotetext{
${ }^{1}$ (ptoro@uahurtado.cl). Académico del Departamento de Historia de la Universidad Alberto Hurtado (Santiago de Chile). Sus líneas de investigación son historia de la educación y de los movimientos estudiantiles en Chile e historia de las emociones. Entre sus publicaciones recientes se encuentran "Towards a new Chile through the heart: aspects on the construction of a nationalist emotionology in school textbooks during Pinochet years (c.1974-c.1984)". History of Education \& Children's Literature, X, 1 (2015), pp. 583-600 y “ ¿Sine ira et studio? Reflexiones y desafíos a la historiografía chilena desde la historia de las Emociones”. Revista de Humanidades, n³6, 2017, pp. 229-248.
} 


\begin{abstract}
The recent social unrest that has been going through Chile for more than a decade poses as its central issue the demand for educational changes that overcome a system which rests primarily on market mechanisms and the weakening of public education, legacies of the civil-military dictatorship led by Augusto Pinochet (1973-1990). From this context, the purpose of this article (with some elements of an essay) is to provide a selection of historical junctures in which education is brought into dialogue with the foundations of the social pact and the changing notions of the social good that education provides.
\end{abstract}

Key-words: Chilean education, social pact, Teaching State, Right to Education.

\title{
Introducción
}

En el amanecer del siglo XXI un estudiante santiaguino de enseñanza media, Vicho, se despedía de su liceo con ira y frustración al terminar su último curso. Sentía que no eran ciertas las promesas que escuchó durante tanto tiempo. Eran esas mismas que esperanzaron a sus padres: que la educación es una herramienta de movilidad social y que abre caminos para tener mejores perspectivas en la vida. Que estar en la escuela emancipa, enriquece, entrega un espacio de acogida y pertenencia. Para Vicho, en su experiencia a sus $17 \mathrm{o}$ 18 años de edad, nada de eso resultó cierto pues:

\begin{abstract}
"hace cuatro años, creí inocentemente que lloraría en mi graduación, que te echaría de menos, que le diría a todo el mundo con orgullo que estudié en tus aulas. Pero no, a tan poco tiempo de liberarme de tu corbata y tu insignia, de tu himno y tu corte de pelo varonil, sólo siento lo que cualquiera que vino por manzanas y le dieron peras siente... Frustración es la palabra (...) son muchos los que se fueron, que nos vamos y que se irán y todos tenemos derecho a basurearte como sólo tú te mereces, por no darme lo que debías y condenarme a querer olvidar estos cuatro años de mi vida"2.
\end{abstract}

La rabia de Vicho contra su liceo es difícilmente aislable de dos elementos del imaginario colectivo nacional acerca de la educación en nuestros tiempos y que se acercan al eje de análisis que deseamos plantear en estas páginas. El primero de ellos es la constatación de que, tal como reza "El baile de los que

2 "Carta de despedida de un frustrado a su liceo". En: Revista Perro Muerto No3, Año 1. Santiago: Diciembre-Marzo 2001, p. 8. Citada en Daniel Fauré Polloni, Prácticas auto-educativas de la juventud urbano popular en el Chile post-dictatorial: saberes, control comunitario y poder popular territorial (Santiago, 1987-2013), Tesis Doctoral en Historia, Universidad de Chile, 2015, p.378. 
sobran", la emblemática canción de 1986 del grupo musical Los Prisioneros, para muchos estudiantes bajo el Chile neoliberal se ha hecho habitual una suerte de desesperanza aprendida respecto al sentido de la educación. Ha proliferado la queja de que "a otros enseñaron secretos que a ti no/ a otros dieron de verdad esa cosa llamada educación/ ellos pedían esfuerzo, ellos pedían dedicación/ ¿y para qué? para terminar bailando y pateando piedras"3. Esa sensación, que horada el alma, es doblemente dramática cuando se cruza con el segundo elemento que nos parece necesario rescatar: la nostalgia respecto a una educación (nebulosamente identificada como pública) que, anclada a un tiempo ido, habría sido robada a la comunidad nacional en su calidad de bien público y social. Así, Joaquín, otro joven estudiante secundario (en algún grado más favorecido que Vicho, por pertenecer a un establecimiento de excelencia académica), señalaba en 2010, ya en un contexto de masivas movilizaciones estudiantiles en pos de cambios educacionales, que:

"antiguamente la educación era excelente. Todo este proceso empieza con Eduardo Frei Montalva [Presidente de Chile en 1964-1970], la educación es para todos, pero ¿qué calidad de educación le vamos a dar a todos? ¿En qué momento nos despreocupamos de la calidad?, ahí empieza el problema, y peor es cuando se introduce la educación al libre mercado, al sistema neoliberal. Ahí matamos a la educación chilena"4.

No sería tolerable en modo alguno sostener que tanto Vicho como Joaquín interpretaban erróneamente la realidad educacional en la que les correspondió estar insertos. El valor de la experiencia personal, la formación de convicciones o el tránsito a través de paisajes emocionales específicos no pueden ser remitidos, en calidad de correctos o errados, a constataciones sustentadas en la autoridad de la palabra académica ni debe emplearse recurso alguno que tienda a desconocer y/o minimizar a la subjetividad como terreno digno de atención de parte de la historiografía. Más allá de semejante tentación, creemos que resulta hermenéuticamente fructífero acercarse con atención y respeto a ambos testimonios y tomarlos como posibles puntos de partida para una interlocución, un diálogo con una mirada histórica beneficiada por un horizonte temporal más amplio. En la rabia de Vicho y en la nostalgia de Joaquín encontramos disposiciones anímicas que se inscriben en el área de interés de este texto y que permiten argumentar, a partir de esas percepciones, en clave analítica. Así, en las siguientes páginas se intenta esbozar una breve visión interpretativa de algunos aspectos de la educación chilena recurriendo, principalmente, a un enfoque histórico. En virtud de ello, se ha seleccionado tres núcleos cronológicos de la historia

\footnotetext{
3 "El baile de los que sobran", en el álbum Pateando piedras. Santiago, EMI, 1986.

${ }^{4}$ Entrevista a Joaquín Valderrama Salinas, estudiante del Instituto Nacional, en Tamara Gutiérrez Portillo y Cristina Caviedes Reyes, Revolución Pingüina. La primera gran movilización del siglo XXI en Chile, Santiago, Editorial Ayún, 2010, p. 32.
} 
educacional chilena $(1810,1910,2010)$ que aparecen como pertinentes para someter a cuestión un problema transversal que guía a este texto: la comprensión acerca de qué significa, en contextos lejanos y recientes, la educación como parte de un pacto colectivo y en qué medida se articula con el problema de la felicidad, entendiendo a ésta como un fenómeno con dimensión social.

Para emprender este trayecto, hemos recurrido, de modo muy sucinto e instrumental, a dos insumos principales. En primer lugar, a la guía que significan las reflexiones de Hannah Arendt respecto a la felicidad como uno de los fundamentos posibles para la legitimidad de la política moderna. Como segundo apoyo, recurrimos a la revaloración que se ha hecho, en el marco de las ciencias sociales y la historiografía reciente, del papel que cumplen las emociones como cohesionadores de la acción colectiva y elementos de posible validación de la movilización política, buscando rebasar los límites de una comprensión de lo público hecha exclusivamente a partir de la razón instrumental y de la asepsia implícita a la reducción de lo político únicamente a lo técnico, tendencias ambas que campean en estos tiempos.

Sobre la primera referencia, interesa sobre todo para nuestro análisis integrar sumariamente una apreciación que Arendt elabora respecto a lo público en los escenarios revolucionarios fundacionales de la modernidad política: los procesos de Francia y Estados Unidos en el último tercio del siglo XVIII. Independientemente de la precisión que pueda hallarse en la base histórica de su comprensión de ambos procesos, el examen de Arendt desde el punto de vista de las ideas resulta sumamente sugerente. Mirando a una misma época, a ambos lados del océano, Arendt identifica fuerzas conceptuales divergentes en los desarrollos fundantes de lo republicano: en Francia la revolución tiene un componente medularmente igualitario, surgido de la constatación cercana del abuso absolutista y de la precariedad material de las masas, el imperio de la necesidad, que rápidamente tiene como resultado la elaboración de la figura del bienestar común o felicidad del pueblo como sujeto moral, relegando a un segundo plano las dimensiones libertarias potencialmente implícitas en una ruptura radical con el pasado. Por su parte, la revolución de independencia de los Estados Unidos tendría, en la interpretación arendtiana, un sentido de fundación más que de liberación, dado que se definiría a partir de una retórica (recogida en su Declaración de Independencia) en que la comunidad política se constituye a partir de una búsqueda de satisfacción entendida "como bienestar privado y como derecho a la felicidad pública, como la prosecución del bienestar y como la participación en los asuntos públicos"5. En la matriz original de la revolución norteamericana no sería posible limitar la felicidad a un hecho aislado sino que a una construcción también necesariamente gregaria, de interdependencia y colaboración en la búsqueda de la felicidad (the pursuit of happiness).

\footnotetext{
${ }^{5}$ Hannah Arendt, Sobre la revolución, Madrid, Alianza Editorial, 1988, p.132.
} 
A partir de la referencia al problema de la búsqueda de la felicidad como leit motiv inicial de la revolución norteamericana, emerge el segundo insumo que hemos escogido para enmarcar nuestro recorrido histórico: el problema de las emociones como un factor de lo público. En este sentido, efectivamente los aspectos emocionales cumplen un papel de potenciales agentes de cohesión en sociedades crecientemente diversas. La existencia misma de la sociedad y la civilización se deben, entre otros factores, al despliegue de emociones apropiadas, de modo tal que, en perspectiva sociológica, cuando un grupo dominante no tiene la capacidad o voluntad de apoyar los requisitos emocionales necesarios para el funcionamiento del colectivo, esa sociedad tiende a la fragmentación y crisis ${ }^{6}$. Por ello, la educación resulta de crucial importancia como uno de los vehículos privilegiados para difundir un sentido emocional colectivo (por ejemplo, el recurso al nacionalismo como comunidad imaginada, siguiendo la figura propuesta por Benedict Anderson). Así, las emociones cumplen un rol de orientación y motivación para la formación de la acción colectiva. En tal sentido, la atención reciente que se les ha brindado a sus dimensiones emocionales, desafiando el binario tradicional de razónemoción y norma-ruptura, ha estado ayudando a entender tanto los dilemas estratégicos como los procesos de toma de decisiones que despliegan los movimientos sociales ${ }^{7}$. La transformación y uso de estados emocionales como rótulos de identidad política (como, por ejemplo, con el movimiento global de los indignados) forma parte de un escenario que ha reactivado el interés por este campo de la realidad social.

En la línea de pensar a las emociones como articuladoras colectivas de la acción social, tanto en un plano contingente como estratégico, es que resulta posible introducir la consideración del problema de la felicidad como asunto no solamente de filosofía política general (ángulo sobre el cual nos ilustra la reflexión de Arendt), sino que de explícito valor para la práctica de la política en los tiempos que corren. En años recientes ha sido posible apreciar que la felicidad se ha inscrito en el repertorio de los problemas de la gestión política, principalmente a partir de su valorización (por ser medible, supuestamente) como índice complementario a las formas tradicionales de señalar y comparar el bienestar de una población. Así, de ser un asunto de interés principalmente para la filosofía desde Aristóteles en adelante, la felicidad repentinamente ha devenido, en palabras de Eugenio Tironi (que cita un artículo de 2016 de The Economist), en un campo temático copado por los economistas y que ha

\footnotetext{
${ }^{6}$ Joseph de Rivera, Emotions and the formation of social identities, [en Mikko Salmela and Christian von Scheve (Eds.), Collective emotions: perspectives from psychology, philosophy, and sociology. Oxford, Oxford University, Press, 2014], p.218."

7 James Jasper, "Las emociones y los movimientos sociales: veinte años de teoría e investigación", en Revista Latinoamericana de Estudios sobre Cuerpos, Emociones y Sociedad-Relaces, 10, (2012), p.49.
}

Araucaria. Revista Iberoamericana de Filosofía, Política y Humanidades, año 19, ${ }^{\circ} 38$. Segundo semestre de 2017. Pp. 323-344. ISSN 1575-6823 e-ISSN 2340-2199 doi: 10.12795/araucaria.2017.i38.14 
dado paso a una suerte de "ciencia nueva". Este nuevo campo, entrevero de management, marketing y políticas públicas, ha tenido un singular desarrollo en el caso chileno. De acuerdo a Iván Pincheira, dicho proceso tiene estrecha relación con la índole neoliberal del sistema económico vigente en el país. Siguiendo un enfoque de análisis biopolítico, el autor concluye que "frente a la pérdida de la legitimidad fundada ya sea en la tradición o en premisas teológicas, en una medida importante, será a través de la apelación al recurso a la prosperidad, al bienestar y a la felicidad que dichas adhesiones a las modernas programaciones de gobierno serán suscitadas".

A continuación, teniendo a la vista las breves menciones recién señaladas, se plantea un tránsito por los núcleos históricos que marcan los momentos de origen, evaluación crítica y actualidad de la educación chilena. En esta suerte de sobrevuelo por épocas de distinto tono, se busca relevar ideas, testimonios o hechos que se conectan íntimamente con los ejes de interés que hemos planteado y que, sobre todo, generan posibilidades de diálogo, en clave hermenéutica, con la educación que tiene Chile hoy y la que puede o quiere tener.

\section{0: fijar el principio del pacto social. La educación es política}

En el primer núcleo histórico que interesa abordar en estas páginas se encuentran las formulaciones tempranas de la estrecha identidad entre el pacto social republicano y la educación pública. La comunidad política, establecida en virtud de una ruptura con la metrópolis colonial, requería forjar lazos duraderos entre sus integrantes. Más allá del despliegue de un nuevo orden legal, que se expresaría en la implementación de varios cuerpos constitucionales durante los primeros decenios de vida independiente, se confiaba en que la cohesión de la novel república se debía gestar en cada ciudadano desde las edades tempranas de la vida. Si bien ley, soberanía y capacidad de ejercer el poder mediante la fuerza eran fundamentos indispensables para el nuevo orden republicano, se entendía que se lograrían encarnar en los nacionales solamente mediante la generalización del acceso a la educación. Puede resumirse la centralidad de la educación para el episodio independentista, así como la expectativa asociada a ella, mediante la certera frase con que Sol Serrano sintetiza el problema: "con la Independencia, la educación no es "una" política, sino que "es" política porque se le concibe desde y en función de la nueva soberanía"10.

\footnotetext{
8 Eugenio Tironi Barrios, "La producción de la felicidad y la paradoja latinoamericana", en Societas 18, (2016), p.20.

9 Iván Pincheira Torres, "La gestión gubernamental de las emociones en el Chile neoliberal", en Liminales. Escritos sobre Psicología y Sociedad v. I, 1 (2012), p. 64.

${ }^{10}$ Sol Serrano, "Educar al Nuevo Soberano. Chile entre 1810 y 1814", en Bordón 62 (2), 2010, p. 30 .
}

Araucaria. Revista Iberoamericana de Filosofía, Política y Humanidades, año 19, n 38. Segundo semestre de 2017. Pp. 323-344. ISSN 1575-6823 e-ISSN 2340-2199 doi: 10.12795/araucaria.2017.i38.14 
El lazo íntimo entre educación y establecimiento del nuevo orden político se pudo apreciar cuando aquella apareció inscrita en las primeras disposiciones constitucionales en el mismo nivel de importancia que las garantías individuales. Juan Egaña, redactor del Proyecto de Constitución para el Estado de Chile, en función del encargo recibido por el Primer Congreso Nacional de 1811, señalaba en el primer esbozo constitucional, publicado en 1813, que:

"los gobiernos deben cuidar de la educación e instrucción pública, como una de las primeras condiciones del pacto social. Todos los Estados degeneran y perecen a proporción de que se descuida la educación y faltan las costumbres que la sostienen y dan firmeza a los principios de cada gobierno. En fuerza de esta convicción, la ley se contraerá especialmente a dirigir la educación y las costumbres en todas las épocas de la vida del ciudadano (...)"11.

Se ha interpretado que esta formulación es el punto de origen del Estado Docente, o sea, de la afirmación del rol conductor que la autoridad estatal debe tener sobre la educación, formando un sistema nacional. Esta noción articuladora de las discusiones político-educacionales a lo largo de la historia independiente de Chile ha tenido, a lo menos, dos énfasis principales. El primero fue el que se estableció a partir de los conflictos de carácter principalmente curricular que enfrentaron a sectores clericales y laicistas, episodio que se manifestó con claridad a partir de la década de 1870 y que se proyectó desde entonces como un clivaje importante en el campo educacional. El segundo acento, más propio del proceso masificador de la educación durante el siglo XX, apunta a la noción no solamente de un Estado que tiene hegemonía curricular sobre el sistema de educación sino que además incide determinantemente sobre él, en términos de gestión y propiedad. Ambas dimensiones de la noción de Estado Docente fueron entendidas como divisas de progreso democratizador por fuerzas políticas de centro e izquierda y vistas como amenazas por sectores amparados en versiones clásicas del liberalismo y/o en fundamentaciones religiosas respecto a la anterioridad de la familia frente al Estado a la hora de tomar decisiones sobre la provisión de educación. En un giro más bien de respuesta a la coyuntura política y algo ayuno de contenido, durante el gobierno del presidente Sebastián Piñera (2010-2014), el propio mandatario puso en circulación la figura de "Sociedad Docente", que había sido acuñada en 1989 en el programa presidencial de Hernán Büchi, candidato del saliente gobierno de Augusto Pinochet para las elecciones de ese año. Con ello se intentaba sostener que la sociedad (que estaría representada en las familias) debería ser la detentora legítima de la decisión sobre la educación.

${ }^{11}$ Sesiones de los Cuerpos Legislativos de la República de Chile, 1811 a 1845 (tomo I: 1810-1814), Santiago, Imprenta Cervantes, 1887, p.214.

Araucaria. Revista Iberoamericana de Filosofía, Política y Humanidades, año 19, n 38. Segundo semestre de 2017 Pp. 323-344. ISSN 1575-6823 e-ISSN 2340-2199 doi: 10.12795/araucaria.2017.i38.14 
$\mathrm{Si}$ bien el Estado Docente chileno no era un concepto que guiara explícitamente a los Padres Fundadores de la educación chilena (que debían, más bien, responder a la urgencia de su tiempo presente), se puede apreciar el deseo de centralización curricular en las prioridades del naciente gobierno nacional, expresadas en un oficio de inicios de 1811, de autoría de Manuel de Salas, uno de los fundadores de la política educacional chilena. Para Salas el propósito de la educación pública sería que "(...) reunidos los alumnos recibirían las primeras impresiones uniformes que servirían de base a las virtudes y ocupaciones que más importan a nuestra constitución y que han de inspirarse desde la edad tierna a los que se crían para sostenerla" ${ }^{2}$. En consonancia con esta afirmación sobre qué se debía enseñar, Camilo Henríquez (otro de los fundadores de la educación republicana) señalaba que el Estado debía tener la atribución de ejercer un control administrativo de las escuelas, ya que:

\begin{abstract}
"siendo, pues el soberano moderador supremo del cuerpo civil, y siendo tan importante el buen régimen de las escuelas debe tenerlas bajo su inmediata inspección, como han hecho los príncipes en la creación de las universidades y academias, y debe saber las opiniones dominantes para moderarlas y corregirlas"13.
\end{abstract}

Con todo, los primeros gestores de la educación nacional, reconociendo continuidad con orientaciones propias del Estado absolutista, consideraron como función legítima del Estado (aunque no monopólica) la centralización de la educación, dado que el rol conductor "no era concebido como antagónico a la educación privada y menos a la religiosa" 14 . Probablemente en ello estaba en juego tanto una filiación intelectual de ellos con el pensamiento proveniente de la ilustración católica, por una parte, así como también (de acuerdo a lo que propone Vasco Castillo para el caso de Juan Egaña y su idea de la no tolerancia religiosa) una idea política y republicana de la religión católica como elemento que sería un valioso auxiliar para cohesionar y formar la virtud cívica ${ }^{15}$. Agregaríamos, en clave de extensión a este argumento, que el carácter bifronte de lo religioso (como fenómeno normativo orientado necesariamente a integrar lo individual y lo colectivo, al domos y a la polis) puede haber sido tenido en cuenta como criterio para depositar en él expectativas de cohesión, la que los lenguajes provenientes del liberalismo no estarían totalmente en condiciones de satisfacer, en la crítica coyuntura de organizar el Estado Nación.

${ }^{12}$ Citado por Carlos Ruiz Schneider, De la República al Mercado. Ideas educacionales y política en Chile, Santiago, LOM, 2010, p.17.

13 Educación, "La Aurora de Chile", 9 de abril de 1812, p.1.

14 Sol Serrano, Universidad y Nación. Chile en el siglo XIX, Santiago, Editorial Universitaria, 1994, p.39-40.

${ }^{15}$ Vasco Castillo, La creación de la República: la filosofía pública en Chile, 1810-1830, Santiago, LOM, 2009, p.45. 
Para cumplir las tareas recién señaladas, era fundamental hallar una definición práctica de qué significaba educar, en términos de cómo se debía ejecutar la tarea que tendría como producto el basamento de la comunidad política en construcción. En tal sentido, no es aventurado señalar que la cisura que significó el quiebre colonial, con el consecuente repudio al pasado educacional, generó (retóricamente, más que en la práctica) un espacio vacío en términos pedagógicos y que éste debía ser llenado rápidamente con alguna propuesta apropiada a las necesidades del momento. Así, en un contexto en el que la enseñanza tenía una matriz escolástica y una pedagogía memorística, se consideró oportuna la adopción del método de enseñanza mutua o monitorial. Al método Lancaster, como se le llamó en Chile, se le vio como una solución ejemplar a la necesidad de maximizar los escasos recursos y habilitar a la mayor cantidad de estudiantes en los conocimientos básicos para hacer viable el surgimiento de una ciudadanía capacitada y virtuosa ${ }^{16}$. Las resonancias fabriles y militares del método de enseñanza mutua lograban hacer imaginar que sería posible introducir, por vía de un escaso número de profesores y monitores, una enseñanza masificada que tendría la virtud de operar de modo metafórico, en la medida que transmitiría a través de su propia ejecución como acción didáctica una pedagogía del control del cuerpo, los movimientos, el dominio de las pasiones y la convivencia con el colectivo. Autoritaria y mecánica como era, la enseñanza lancasteriana insinuaba el adviento de la masa como referencia y destinataria de la educación. No obstante, el método cayó en desgracia y fue arrastrado por las tormentosas coyunturas políticas por las que atravesó Chile durante la década de 1820 .

En el mismo terreno de qué significaba educar, resulta iluminador el propósito inicial que tuvo el Instituto Nacional, establecido en 1813 y que volvió a abrir sus puertas tras el período de la reconquista española (1814-1817). En la imagen que los Padres Fundadores del proceso chileno manejaban respecto a qué tipo de conocimiento era necesario para la forja de la República cabían múltiples áreas. De tal modo, el Instituto Nacional estuvo pensado durante algún tiempo como un plantel al que se accedería en base al interés y el mérito, sin importar los pergaminos familiares o la fortuna. En él se estudiaría una amplia gama de saberes, asociando lo científico, técnico, militar y humanístico. Todavía se notaba alguna expectativa de que este tipo de educación sucediera en el Instituto hacia 1822, cuando ya estaba definido el proceso de emancipación. En noviembre de ese año se anunciaba la llegada al país de Carlos Ambrosio

${ }^{16}$ Sobre el método Lancaster o de enseñanza monitorial, la información más tradicional que recoge mayores detalles se halla en la obra de Domingo Amunátegui Solar El sistema de Lancaster en Chile $y$ en otros países sudamericanos, Santiago, Imprenta Cervantes, 1895. Un estudio que inscribe el tema de la influencia y circulación de ideas pedagógicas en el contexto de los primeros pasos de la organización de la educación republicana chilena, con foco en los trabajos organizativos del Instituto Nacional, se encuentra en "Andrés Baeza Enlightenment, education, and the republican project: Chile's Instituto Nacional (1810-1830)", en Paedagogica Historica, 46: 4, (2010), pp.479-493. 
Lozier, educador francés, quien se haría cargo de la rectoría del Instituto Nacional. En la nota al respecto, publicada en El Mercurio de Chile, redactado por Camilo Henríquez, se señalaba entusiastamente que con la llegada de Lozier sería posible "aplicar los conocimientos adquiridos y que se adquieran en el estudio de la química, de la mecánica y de la geometría descriptiva, a todos los ramos de la industria agrícola y manufacturera, y a la aritmética a la industria mercantil"'. Sobrevivía todavía la expectativa de integración de conocimientos de distinta matriz, aunados por la referencia común a su valor para construir la comunidad republicana y fundar el pacto social sobre la educación común, de libre acceso y definida por su valor público. El tiempo se encargaría de evitar la concreción de esos afanes primigenios, haciéndolos encallar contra los intereses corporativos, las preferencias sociales y el peso de tradiciones culturales de profundo arraigo que conspiraron contra este afán integrador. Así, a fines del siglo XIX, se ponderaría con algo de nostalgia esa misión no lograda por el "primer foco de luz de la Nación”, como se denominó al Instituto Nacional. Un agudo analista indicaba que, en su formulación original,

"El Instituto era una obra revolucionaria. Iba a concluir con la educación privilegiada que en la colonia se reservaba solo a los hijos de los nobles, y se proyectaba hacer de él un seminario en el cual todo el que quisiera, sin distinción de clases ni de fortuna, recibiese la enseñanza más extensa y más práctica posible" 18 .

En el marco de esta etapa fundacional, la dimensión esencialmente política de la educación pensada por sus Padres Fundadores en el caso chileno (nada menos que la de crear y criar a la esfera deliberante republicana) podría ser mirada en, a lo menos, dos formas. Por un lado, desde un talante analítico, es posible constatar que, compartiendo los procesos que se vivían en el conjunto de los países americanos tras la ruptura colonial, la educación chilena estaba mandatada para cumplir con su inherente rol reproductivo (vale decir, operar como un dispositivo que legitimara las jerarquías y reforzara las estructuras sociales, no obstante el cataclismo político reciente) pero el lenguaje revolucionario la destacaba, sobre todo, por una dimensión productiva. Ésta involucraba enfrentar y superar tres grandes retos tras el quiebre colonial, que fueron comunes a los países hispanoamericanos: la consolidación de una nueva esfera política, la invención del nuevo orden republicano y una reformulación satisfactoria de las identidades heredadas del pasado colonial ${ }^{19}$.

\footnotetext{
${ }^{17}$ Domingo Amunátegui Solar, Los primeros años del Instituto Nacional (1813-1835), Santiago, Imprenta Cervantes, 1889, p.272

${ }_{18}$ Amunátegui Solar, Los primeros años del Instituto Nacional, p.84.

${ }_{19}$ Marcelo Caruso presenta esta conceptualización sobre las dimensiones reproductiva y productiva de la temprana educación republicana en su interesante artículo "Latin American independence: education and the invention of new polities", en Paedagogica Historica, 46: 4, (2010): 412.
} 
A esa primera mirada es posible agregar otra que, en una perspectiva normativa, política y ciudadana, se haga heredera del valor que hay en que los fundamentos republicanos hayan nacido indisolublemente atados a la educación y que, por lo tanto, considere al episodio de la independencia como un espacio en el que se expresó un potencial de emancipación más integral que la simple ruptura colonial. En esta línea interpretativa (como se argumentará hacia el final de este texto) el pasado fundante del pacto social republicano deja de ser un problema histórico, en tanto asunto del pasado, y deviene en asunto de renovada actualidad. Para decirlo en términos más cercanos a la narrativa, tras doscientos años de vida independiente, puede leerse a los episodios iniciales como el tiempo de una fundación republicana bajo una promesa de felicidad pública cuyo vehículo privilegiado sería la educación. A continuación, se plantea una visión esquemática al estado de ese compromiso tras cien años de vida como nación independiente.

\title{
1910: "me parece que no somos felices". Una educación bajo crítica
}

Apenas despuntaba el nuevo siglo, el radical Enrique MacIver (un reconocido político del sistema parlamentario de matriz oligárquica que imperaba en el país en la época) pronunciaba un discurso que el tiempo terminó por convertir en un manifiesto generacional de descontento y preocupación frente a la pérdida de lo que el autor identificaba como un factor clave para la unidad nacional: la moralidad pública. Señalaba MacIver que:

\begin{abstract}
"me parece que no somos felices; se nota un malestar que no es de cierta clase de personas ni de ciertas regiones del pais, sino de todo e1 pais y de la generalidad de los que lo habitan. La holgura antigua se ha trocado en estrechez, la energía para la lucha de la vida en laxitud, la confianza en temor, las expectativas en decepciones $(\ldots)^{\prime 20}$.
\end{abstract}

El malestar de MacIver se convertiría en un estado anímico compartido por voceros de los más distintos sectores de opinión a medida que se acercaba el Centenario de la independencia. En ello tenía un papel medular la toma de razón respecto a las profundas brechas sociales existentes al interior del país, así como la creciente crisis de legitimidad de un sistema político que, no obstante su funcionamiento regular desde el punto de vista institucional en comparación con el marco latinoamericano, operaba de modo excluyente respecto a los intereses de la mayoría de la población. En los juicios condenatorios acerca del rumbo no deseado que había seguido la promesa original de un pacto

\footnotetext{
${ }^{20}$ Enrique Mac Iver, Discurso sobre la Crisis Moral de la República, Santiago, Imprenta Moderna, 1900 , p.5. 
social tras un siglo de progreso desequilibrado, uno de los factores a los que se hacía mención regularmente era a la educación. Grandes foros de discusión sobre el estado de la enseñanza en Chile y sobre las políticas para mejorarlo se plantearon en 1902 (Congreso General de Enseñanza Pública) y 1912 (Congreso Nacional de Enseñanza Secundaria). En ellos y en una copiosa literatura crítica, crecientemente especializada en temas educacionales, se argumentó en torno a grandes ejes de discusión. En todos ellos estaba implícito el rol del Estado como guía en la articulación de un sistema educacional integrado que, de acuerdo al diagnóstico compartido, había sido pensado originalmente como tal y que no fue efectivamente implementado a lo largo del siglo XIX. De uno u otro modo, la discusión del Centenario fue también un gesto que podría interpretarse como una añoranza respecto a una promesa incumplida o pendiente: el pacto social, fundado en la educación para todos, era una figura ideal pero borrosa, de duro contraste frente a la cruda realidad de un país socialmente polarizado, políticamente oligárquico, económicamente desigual y temeroso de las imprevistas consecuencias de todos estos abismos que separaban a la nación.

Uno de los temas cruciales en la discusión fue la orientación general del sistema, que dividía en la época a los polemistas entre quienes apostaban por una formación humanística y aquellos que enfatizaban la necesidad de darle prioridad a la enseñanza técnica, práctica y comercial. Además de esta polémica, se agitó el tema de la obligatoriedad de la enseñanza primaria, en términos de si era demandada socialmente y si sería conveniente, en términos políticos y sociales, establecerla. Por último, el papel que debía desempeñar el Estado en la implementación de la obligatoriedad fue otro de los asuntos que animó el debate entre los distintos campos políticos y educacionales ${ }^{21}$.

A diferencia del beneficio supuesto que involucraba postular un orden educacional que no reconociera filiaciones con el pasado ni herencias gravosas, como fue el escenario que les tocó enfrentar a los Padres Fundadores de la educación chilena a inicios del siglo XIX, para quienes miraban los rumbos educacionales de comienzos del siglo XX el desafío era doble: enmendar y proponer. Se debía operar sobre una realidad heredada, a la que, en general, se miraba como una tara más que como un punto de apoyo. Al iniciar el Congreso General de Enseñanza Pública en 1902, el reputado educador Juan Nepomuceno Espejo diagnosticaba que:

"La mayor actividad social y económica del país ha despertado nuevos intereses y con ellos nuevas necesidades a las cuales ha tenido que adaptar sus formas la enseñanza. Esta se ha extendido libre y desordenadamente; pero

${ }^{21}$ Este elenco de problemas está analizado de manera sintética y clara en el artículo de Andrés Donoso Romo y Sebastián Donoso Díaz, "Las Discusiones Educacionales en el Chile del Centenario", en "Estudios Pedagógicos” XXXVI, 2, (2010), pp. 295-311. 
al extenderse y separar sus ramas, ha perdido su unidad orgánica y olvidado el fin común que le señalaron nuestros padres"22.

En las palabras de Espejo se traslucía un reconocimiento a las profundas transformaciones sociales y económicas que Chile estaba experimentando desde la década de 1880: una expansión económica sostenida, apoyada sobre la exportación de salitre; un proceso creciente de urbanización y sus consiguientes demandas sobre el aparato educacional; la configuración de nuevos actores sociales que depositaban expectativas crecientes respecto a la educación, entre otros factores. Si bien el sistema escolar se expandió rápidamente durante el período posterior al triunfo chileno en la denominada Guerra del Pacífico (1879-1883), no pareció adoptar una forma sistemática ni una definición de fondo respecto a sus propósitos generales. Por eso es que en el alegato de los analistas de la época del Centenario la contraposición entre las dos orientaciones posibles, unida a la falta de correlación entre la enseñanza primaria y la educación secundaria, sintetizaba clivajes cruciales, como bien lo expresa la siguiente cita de Darío Salas en que denunciaba:

"el unilateralismo que ve incompatibilidad entre la educación general y la especial y que llama a la una aristocrática y a la otra democrática; que cree que la una forma a la clase directiva y la otra a la clase productora; que asigna a la primera "la formación del hombre" mediante la persecución del ideal imposible de desarrollar armónicamente al individuo, y a la segunda, la de habilitarlo para ganarse la vida cultivando en el sólo determinadas aptitudes (lo que podrá estorbar su desenvolvimiento armónico, pero que lo hará no ser nota discordante en la armonía del conjunto)"23.

Los disensos en torno a qué rumbo debía tomar la educación y la polémica respecto a su falta de organización como sistema de formación continua se vieron potenciados por las ingentes muestras de descontento que surgían desde el mundo popular ante el estado de la enseñanza. Adiferencia de los inicios de la vida republicana, en que Egaña, Salas y otros promotores iniciales de la instrucción pública obraban sin que existiera manifestaciones desde la contraparte (o sea, desde la demanda por educación), en el Centenario ya existía una tradición acumulada de expresiones populares de expectativas y de valoración respecto al avance de la escolarización. Por ende, la insatisfacción frente al estado de la instrucción pública cundió entre los movimientos populares, siendo expresada, por ejemplo, en estas críticas palabras de Luis Emilio Recabarren, dirigente obrero y fundador del partido comunista chileno en 1922. Señalaba Recabarren en los días previos a la celebración del Centenario:

\footnotetext{
${ }^{22}$ Juan N. Espejo, Concepto general de la enseñanza pública [en Congreso General de Enseñanza Pública de 1902, Tomo I, Santiago, Imprenta Barcelona, 1903], p.74.

${ }^{23}$ Darío Salas, Correlación y continuidad de la enseñanza secundaria [en Congreso Nacional de Enseñanza Secundaria 1912, Tomo II, Santiago, Imprenta Universitaria, 1913], p.65
} 
El progreso intelectual en esta época no es un progreso moral, pues en muchos casos la mayor capacidad conduce al individuo a la relajación. El progreso intelectual, creo decirlo sin pasión, se ha desarrollado notablemente en la clase media, y podría ser esto un motivo de alegría, pero la finalidad social que se busca como fruto del progreso intelectual dista mucho aún y la labor del proletariado inteligente prosigue vigorosamente su marcha ${ }^{24}$.

La demanda social y política por educación en la coyuntura del Centenario actualizaba, desde la constatación de la promesa incumplida, la pregunta por el rol del Estado en la provisión de educación universal. Pocos años antes, el Congreso Social Obrero denunciaba "que con un presupuesto como el de Chile, que alcanza para ayudar con setenta millones de pesos a las instituciones bancarias -que sólo benefician directamente a una determinada clase social- sobraría para establecer la educación de todos sus hijos en cualquier país (..."”25. Estas manifestaciones críticas se irían haciendo cada vez más recurrentes durante las dos primeras décadas del siglo XX y se verían acompañadas por la emergencia de iniciativas de auto-instrucción implementadas por grupos de trabajadores, usualmente seguidores de las orientaciones políticas y educativas ácratas. De tal modo, por ejemplo, un movimiento educacional paraestatal, las escuelas federales racionalistas (estudiadas consistentemente por la historiadora Leonora Reyes en el caso chileno) plantearían proyectos basados en la desafección a una enseñanza estatal que, pretendiendo la integración en clave nacionalista, no se había dotado de la herramienta fundamental para cumplir con su propósito: la obligatoriedad de la instrucción primaria. En la crítica anarquista se dejaba ver el disenso radical sobre el propósito de la educación, así como el escepticismo respecto a la prometida y pendiente enseñanza estatal como fundamento del prometido pacto social. Ello quedaba reflejado en noviembre de 1922 en una columna del periódico popular La Federación Obrera de Chile, en la que se sostenía que:

\footnotetext{
"se somete al hombre a tolerar el injusto y criminal régimen social en que los débiles son mantenidos ahora por toda clase de medios. Por tanto la escuela del Estado y la sectaria de todos modos atrofian las facultades intelectivas del niño para que puedan subsistir las castas"26.
}

${ }^{24}$ Luis Emilio Recabarren, Ricos y pobres a través de un siglo de vida republicana [en Julio César Jobet, Jorge Barría y Luis Vitale (compiladores) Obras selectas de Luis Emilio Recabarren, Santiago, Quimantú, 1971] p.260.

${ }^{25}$ La cita, correpondiente a 1901, figura en Mario Monsalve "...i y el silencio comenzó a reinar". Documento para la historia de la instrucción Primaria 1840-1920, Santiago, Dibam, 1998, p.164.

${ }^{26}$ Citado en Leonora Reyes Jedlicki, "Educando en tiempos de crisis. El movimiento de Escuelas Racionalistas de la Federación Obrera de Chile, 1921-1926", en "Cuadernos De Historia" n³1, 2009, p.103.

Araucaria. Revista Iberoamericana de Filosofia, Política y Humanidades, año 19, no 38. Segundo semestre de 2017. Pp. 323-344. ISSN 1575-6823 e-ISSN 2340-2199 doi: 10.12795/araucaria.2017.i38.14 
En un país sometido a cambios acelerados, derivados de una expansión económica inédita durante casi tres décadas en base a exportaciones, acompañada de procesos políticos de representación restringida y crecientemente carentes de hegemonía debido a la crítica social y política de sectores medios y populares, a inicios de la década de 1920 se construyó, por fin, un consenso en la elite respecto a la pertinencia de la obligatoriedad de la instrucción primaria. En las décadas siguientes, nuevas coaliciones político-sociales, representativas de sectores medios, amparadas en un propósito integrador y multiclasista, apostarían a que la educación sería capaz de atemperar tendencias de disociación y conflicto social y, de esta manera, se pondría en marcha un discurso educacional que podría entenderse, de acuerdo a Barr-Melej, como "nacionalista progresivo"27.

Durante el medio siglo siguiente, el sistema educacional chileno tuvo una expansión sostenida. Se experimentó, en el nivel de las políticas (ya que no en el de la polémica entre distintos actores) un pacto tácito entre la idea de un Estado Docente no solamente curricular sino que también gestor y propietario de la oferta educativa, por un lado, y la existencia de una amplia oferta privada que, en determinados contextos expansivos de la matrícula (como, por ejemplo, la década de 1950) se hizo vital en la implementación de la oferta escolar ante una demanda desbordante desde la sociedad ${ }^{28}$. Iniciativas de orden mayor para establecer conexiones efectivas entre los subsistemas educativos se dieron con mayor fuerza desde mediados de la década de 1960, en el marco de los procesos de planeación integral de la enseñanza, promovidos al amparo de la Alianza para el Progreso y la teoría del capital humano. Tras un período de profundas transformaciones, contenidas en el gobierno reformista de Eduardo Frei Montalva (1964-1970), la tentativa de construcción de un sistema transicional hacia el socialismo, bajo el gobierno de la Unidad Popular (1970-1973) actualizó la demanda de fondo por un reconocimiento de la educación como piedra angular del pacto social. De acuerdo al diagnóstico de las autoridades educacionales de la Unidad Popular, un sistema de educación básicamente segregado había llevado a que "en el transcurso de 150 años de independencia política, la población de Chile aún no alcanza un promedio sistemático de formación cultural superior a los 3 años y fracción" ${ }^{29}$. La orientación socialista del plan encabezado por Allende demostró fídelidad al predominio de un lenguaje centrado en la planificación y, paradójicamente, dependiente del concepto de capital humano. Sin embargo, también puso en

\footnotetext{
${ }_{27}$ Patrick Barr-Melej, The nationalist imagination: reformers, cultural politics and the making of an alternative nationalism in twentieth-century Chile, Ph.D. dissertation, University of California at Berkeley, 1998, p.184

${ }^{28}$ Al respecto, Pablo Toro Blanco, "Educational Freedom or Teaching State? Political discussion of the school subvention law in 1951. A key episode on a deep cleavage in the history of Chilean education", en Hungarian Educational Research Journal, Volume 4, Issue 4, November 2014.

${ }^{29}$ Formulación de una nueva educación en el gobierno de la Unidad Popular, Santiago, Ministerio de Educación, 1971, p.11.
}

Araucaria. Revista Iberoamericana de Filosofía, Política y Humanidades, año 19, $\mathrm{n}^{\circ} 38$. Segundo semestre de 2017. Pp. 323-344. ISSN 1575-6823 e-ISSN 2340-2199 doi: 10.12795/araucaria.2017.i38.14 
la discusión el fundamento último de la educación como un derecho social y político, dando continuidad a casi un siglo de debates y propuestas en tal sentido. La interrupción violenta del proceso en 1973, con el Golpe de Estado que derrocó al Presidente Salvador Allende, dio lugar a una transformación radical de los términos de la discusión sobre políticas educacionales, sobre todo a partir de la última parte de la década de 1970, en que se adoptó un modelo que pareció clausurar la ruta de fortalecimiento del Estado Docente (en sus dos acepciones históricas) y que, a la luz de su filosofía política subyacente con base en el mercado y no en la comunidad política, buscaría hipotecar (o, a lo menos, restringir o diluir) la concreción del propósito fundacional de inicios de la vida republicana.

\section{0: Una felicidad de ranking. Una educación (nuevamente) en crisis}

A fines de febrero de 2010 Chile se encontraba expectante debido a, por lo menos, dos razones. Por un lado, tras un largo período de predominio de la alianza política de centroizquierda que, a partir de 1990, condujo la transición política tras la salida del poder del general Pinochet, la derecha política llegaba al poder mediante elecciones. En un par de semanas Sebastián Piñera, el millonario triunfante, llegaría a ocupar el Sillón de O’Higgins. Además, el fin de vacaciones de verano iba a introducir a los chilenos en los preparativos para la conmemoración del Bicentenario de la independencia nacional. Las fuerzas de la naturaleza tenían preparado otro libreto: en la madrugada del 27 de febrero un gigantesco terremoto y posterior tsunami azotó al centro y sur del país causando numerosa pérdida de vidas humanas y graves daños materiales. La agenda política de la administración entrante se vio condicionada, desde allí en adelante, a enfocarse en las tareas de reconstrucción.

En lo que puede haber constituido una sorpresa para muchos, en mayo de 2010 el presidente Piñera solicitó al programa de Naciones Unidas para el Desarrollo (PNUD) la realización de un informe acerca de los índices de felicidad de la población chilena ${ }^{30}$. Siguiendo la discusión reciente respecto a la necesidad de hacer más complejos los instrumentos para percibir el bienestar de las poblaciones, el gobierno chileno se acoplaba a una tendencia innovadora que, al año siguiente, sería recogida por las Naciones Unidas como una orientación general para sus países miembros pues, mediante la resolución 65/309, en abril de 2011, se invitaba a "la elaboración de nuevas medidas que reflejen mejor la importancia de la búsqueda de la felicidad y el bienestar..."31. Las mediciones llevadas a cabo desde allí en adelante traerían resultados interesantes. Así, de

${ }^{30}$ Eugenio Tironi Barrios, La producción de la felicidad..., p.20.

31 Ídem. 
acuerdo al segundo reporte sobre el "índice de felicidad" entregado por la ONU en abril de 2013, Chile avanzaba del puesto 43 al 28 a nivel mundial ${ }^{32}$.

De tal manera, sucedía que Chile se encontraba, poco después de doscientos años de vida independiente, reputado como uno de los países más felices del orbe. Sin embargo, esa felicidad (una sumatoria de indicadores elaborados desde un enfoque con acento en el bienestar material y en las posibilidades de operar sobre ella como parte de políticas públicas) dejaba mucho que desear, en la medida que fuera sometida a análisis en una clave más compleja: recapitulando sobre la vieja noción de felicidad pública. Sobre todo, aquella sería una felicidad incompleta, atendiendo a las carencias y precariedades de su herramienta principal, de acuerdo al discurso de los Padres Fundadores de nuestra república: la educación. Así, el sueño inicial de una educación integrada, que sería matriz para la valoración igualitaria de los ámbitos de lo humanístico y lo técnico (como lo pensaron los fundadores del Instituto Nacional, por ejemplo), se hallaba lejos de cumplirse. En 2013 Chile presentaba una mayor tasa de egresados del sistema de formación científico-humanista (32\%) que de enseñanza técnico-profesional (9\%), marcando un fuerte contraste con los demás países integrantes de la OCDE, que mostraban una tendencia inversa $(12 \% \text { y } 26 \% \text {, respectivamente })^{33}$.

Durante la última década el malestar social respecto a la educación ha aumentado en Chile. Es un tipo de dolencia colectiva que tiene alojadas varias paradojas en su interior. La pérdida del sentido gregario, consistente con procesos de alta individuación, no ha terminado por suceder del todo, mientras que el alegato estrictamente individual no se ha impuesto completamente. Se asiste, entonces, a un momento de crisis en que (como bien lo expresó Brecht) "lo nuevo no acaba de nacer, y lo viejo no termina de morir". Se desea aquello que la educación tiene de solidificadora de los vínculos sociales, de refugio colectivo, pero también se quiere que exista flexibilidad, apertura, indeterminación. Como bien lo sintetiza Carlos Peña:

\begin{abstract}
"en nuestro país, en efecto, esperamos que el sistema escolar contribuya a la cohesión social, pero a la vez sea sensible a la diversidad cultural; que ayude a que los niños y niñas se sometan a la experiencia de la ciudad, pero a la vez exprese las preferencias de la familia; que provea de un relato incondicional que nos identifique, pero al mismo tiempo inculque un espíritu crítico; que provea bienes públicos, pero incentive la prosecución de bienes privados" 34 .
\end{abstract}

32 "Chile sube 15 puestos en ranking mundial de felicidad", en diario La Tercera, 9 de septiembre de 2013 http://www.latercera.com/noticia/chile-sube-15-puestos-en-ranking-mundial-de-felicidad/ (acceso en 2 de mayo de 2017).

${ }_{33}$ Análisis de indicadores educativos de Chile y la OCDE en el contexto de la Reforma Educacional. Revisión comparada de la educación en Chile en el panorama internacional, en base a la publicación Education at a Glance 2015 (con datos 2013), Santiago, Ministerio de Educación, 2015, p. 18.

${ }^{34}$ Carlos Peña González, "Educación y ciudadanía: los problemas subyacentes", en Pensamiento Educativo, volumen 40, n¹, 2007, p. 34. 
En ese escenario, la educación chilena del Bicentenario se ha encontrado sobrepasada por la demanda social. Ello no tiene que ver solamente con un problema de respuesta a las formas clásicas de la demanda (cobertura, mayor número de escuelas) sino que con la complejidad de las tareas nuevas que se le exige. En el plano de su consistencia como producto de la acción humana (un bien económico para algunos; un derecho social, para otros), la educación está mandatada para satisfacer la necesidad de calidad y esa misión parece conducirla en un camino no totalmente compatible con sus otras tareas históricamente asignadas. En tanto la calidad en cuestión resulta una constelación de estándares externamente impuestos que remiten principalmente al ámbito de lo individual y al valor de la competencia como guía suprema, cabe preguntarse cómo puede la educación hacerse cargo de la felicidad pública. O, en una aproximación minimalista, de qué manera es capaz de favorecer la cohesión social.

De acuerdo a una definición mínima formulada por el Consejo de Europa en 2004, la cohesión social se entiende como la "capacidad de una sociedad para asegurar el bienestar de todos sus miembros, al minimizar las disparidades y evitar la polarización" ${ }^{35}$. En tal sentido, puede entenderse que la cohesión es un proceso de construcción perpetua y no un estado al que se pueda arribar. Indicábamos que consistiría en una aproximación minimalista en la medida que es un concepto tanto descriptivo como normativo, pero en esta última dimensión no aflora un componente utópico como el que supone la idea integral de felicidad pública. En aras de esta cohesión social es que se han conducido las políticas educacionales en los años recientes y resulta interesante interpretar a ese concepto, más bien pensado para actuar por oposición (minimizando y evitando) como marco en el que se han rearticulado, en el caso chileno, los términos tradicionales de disputa entre Estado Docente y Libertad de Enseñanza. En tal sentido, es posible notar la existencia de dos líneas de interés que los representarían respectivamente: en el primer caso, la que privilegia una visión del Estado como agente de equidad y, por el contrario, aquella que pone énfasis en la calidad y excelencia de la educación ${ }^{36}$. Cuánta atención brinda cada una de estas líneas de interés a la integración de lo privado y lo público como imbricación indispensable para el logro de la felicidad pública es algo que merece, a lo menos, una reflexión.

\footnotetext{
${ }^{35}$ Gustavo Iaies y Andrés Delich, Sistemas educativos y cohesión social: la reconstrucción de "lo común" en los Estados Nacionales del siglo XXI, [en Simon Schwatzman y Cristián Cox (editores) Politicas educativas y cohesión social en América Latina. Santiago, Uqbar Editores, 2009], p. 183.

${ }^{36}$ Gustavo Iaies y Andrés Delich, Sistemas educativos y cohesión social, p. 218
} 


\title{
Reflexiones finales
}

En una panorámica integral del estado de la educación chilena al inicio del siglo XXI, era imposible no reconocer avances encomiables en distintos campos. Sin embargo, más allá de indicadores satisfactorios de cobertura o de avances en calidad en los distintos campos del sistema educativo, una inquietud de fondo permanecía en un analista del conjunto del sistema, dada la profunda brecha interna que ha subsistido a lo largo de doscientos años y que se ha visto potenciada con políticas indiferentes a la promesa fundante del pacto social o, en términos más modernos, no guiadas principalmente por el afán de brindar cohesión social. Cristián Cox, uno de los conductores de las políticas educacionales en los gobiernos post-dictadura, planteaba en 2003:

\begin{abstract}
¿Será capaz el campo de políticas educativas del país de abordar en forma efectiva los severos límites que establece un sistema escolar segmentado socialmente, de acuerdo con lo que indican sus ampliamente compartidos valores de igualdad de oportunidades y cultura democrática? Un problema y una interrogante que la celebración próxima del Bicentenario merece ver respondidos ${ }^{37}$.
\end{abstract}

Está claro que el Bicentenario llegó; que Chile, larga y angosta faja de tierra, se sacudió desde sus entrañas; que la sociedad civil se movilizó, gritando su rabia y demandando, desde esa extraña nostalgia, volver a donde nunca se estuvo: a esa educación pública y estatal, gratuita, ampliada, de calidad, integradora, progresista, que decora los anaqueles de un pasado que quisiéramos fuera tal. ¿Quién puede decir que los jóvenes estudiantes que, al inicio de estas páginas, manifestaban su desazón y añoranza están radicalmente equivocados? Más que tomar sus palabras por verdad absoluta y elevarlas a la altura de consigna, reduciendo el papel del analista al de comparsa populista de los dictados del día a día, vale la pena imaginar de qué manera esos testimonios no son sino el trasunto de legítimas apropiaciones del pasado, que pueden y deben ser enriquecidas con diálogos más informados con éste. En vez, al contrario, de desestimar por inexacta o subjetiva en extremo esa nostalgia de volver a donde nunca se estuvo, mejor cabe hacer que la historiografía de la educación no se entregue a la tentación de convertirse en un campo de conocimiento inmune a la vida, sordo frente a las esperanzas de quienes consideran, después de doscientos años, que la educación es crucial para el país.

\footnotetext{
${ }^{37}$ Cristián Cox, "Las políticas educacionales de Chile en las últimas dos décadas del siglo XX", [En Cristián Cox (editor) Politicas educacionales en el cambio de siglo. La reforma del sistema escolar en Chile. Santiago, Editorial Universitaria, 2005], p. 104.
} 


\section{Referencias bibliográficas:}

Amunátegui Solar, Domingo: Los primeros años del Instituto Nacional (18131835), Santiago, Imprenta Cervantes, 1889.

Amunátegui Solar, Domingo: El sistema de Lancaster en Chile y en otros países sudamericanos, Santiago, Imprenta Cervantes, 1895.

Análisis de indicadores educativos de Chile y la OCDE en el contexto de la Reforma Educacional. Revisión comparada de la educación en Chile en el panorama internacional, en base a la publicación Education at a Glance 2015 (con datos 2013), Santiago, Ministerio de Educación, 2015.

Arendt, Hannah: Sobre la revolución, Madrid, Alianza Editorial, 1988.

Baeza, Andrés: Enlightenment, education, and the republican project: Chile's Instituto Nacional (1810-1830), "PAEDAGOGICA HISTORICA", 46: 4, (2010), pp.479-493.

Barr-Melej, Patrick: The nationalist imagination: reformers, cultural politics and the making of an alternative nationalism in twentieth-century Chile, Ph.D. dissertation, University of California at Berkeley, 1998.

Caruso, Marcelo: "Latin American independence: education and the invention of new polities", en Paedagogica Historica, 46: 4, (2010), pp. 409-417.

Castillo, Vasco: La creación de la República: la filosofía pública en Chile, 1810-1830, Santiago, LOM, 2009.

Cox, Cristián: "Las políticas educacionales de Chile en las últimas dos décadas del siglo XX", [En Cristián Cox (editor) Políticas educacionales en el cambio de siglo. La reforma del sistema escolar en Chile. Santiago, Editorial Universitaria, 2005], pp.19-113.

de Rivera, Joseph: "Emotions and the formation of social identities", [en Mikko Salmela and Christian von Scheve (Eds.), Collective emotions: perspectives from psychology, philosophy, and sociology. Oxford, Oxford University, Press, 2014], pp.217-231.

Donoso Romo, Andrés y Donoso Díaz, Sebastián: "Las Discusiones Educacionales en el Chile del Centenario", en Estudios Pedagógicos XXXVI, 2, (2010), pp. 295-311.

Espejo, Juan N.: "Concepto general de la enseñanza pública" [en Congreso General de Enseñanza Pública de 1902, Tomo I, Santiago, Imprenta Barcelona, 1903], pp.74-80.

Fauré Polloni, Daniel: Prácticas auto-educativas de la juventud urbano popular en el Chile post-dictatorial: saberes, control comunitario y poder popular territorial (Santiago, 1987-2013), Tesis Doctoral en Historia, Universidad de Chile, 2015. 
Formulación de una nueva educación en el gobierno de la Unidad Popular, Santiago, Ministerio de Educación, 1971.

Iaies, Gustavo y Delich, Andrés: "Sistemas educativos y cohesión social: la reconstrucción de 'lo común' en los Estados Nacionales del siglo XXI', [en Simon Schwatzman y Cristián Cox (editores) Políticas educativas y cohesión social en América Latina. Santiago, Uqbar Editores, 2009], pp.179-234.

Jasper, James: "Las emociones y los movimientos sociales: veinte años de teoría e investigación", en "Revista Latinoamericana de Estudios sobre Cuerpos, Emociones y Sociedad-Relaces", 10, (2012), pp.48-68.

"LA AURORA DE CHILE", 9 de abril de 1812.

"LA TERCERA", 9 de septiembre de 2013.

Mac Iver, Enrique: Discurso sobre la Crisis Moral de la República, Santiago, Imprenta Moderna, 1900.

Monsalve, Mario: “...i y el silencio comenzó a reinar”. Documento para la historia de la instrucción Primaria 1840-1920, Santiag, Dibam, 1998.

Peña González, Carlos: "Educación y ciudadanía: los problemas subyacentes", en Pensamiento Educativo, volumen 40, n²1, 2007, pp.31-43.

Pincheira Torres, Iván: "La gestión gubernamental de las emociones en el Chile neoliberal", en "Liminales. Escritos sobre Psicología y Sociedad” v. I, 1 (2012), pp.54-68.

Recabarren, Luis Emilio: "Ricos y pobres a través de un siglo de vida republicana" [en Julio César Jobet, Jorge Barría y Luis Vitale (compiladores) Obras selectas de Luis Emilio Recabarren, Santiago, Quimantú, 1971].

Reyes Jedlicki, Leonora: "Educando en tiempos de crisis. El movimiento de Escuelas Racionalistas de la Federación Obrera de Chile, 1921-1926”, en Cuadernos de Historia n³1, 2009, pp.91-122.

Ruiz Schneider, Carlos: De la República al Mercado. Ideas educacionales y politica en Chile, Santiago, LOM, 2010.

Salas, Darío: "Correlación y continuidad de la enseñanza secundaria" [en Congreso Nacional de Enseñanza Secundaria 1912, Tomo II, Santiago, Imprenta Universitaria, 1913], pp.64-76.

Serrano, Sol: Universidad y Nación. Chile en el siglo XIX, Santiago, Editorial Universitaria, 1994.

Serrano, Sol: "Educar al Nuevo Soberano. Chile entre 1810 y 1814", en Bordón 62 (2), 2010, pp.29-38.

Sesiones de los Cuerpos Legislativos de la República de Chile, 1811 a 1845 (tomo I: 1810-1814), Santiago, Imprenta Cervantes, 1887.

Tironi Barrios, Eugenio: "La producción de la felicidad y la paradoja latinoamericana", en Societas 18, (2016), p.19-27. 
Toro Blanco, Pablo: "Educational Freedom or Teaching State? Political discussion of the school subvention law in 1951. A key episode on a deep cleavage in the history of Chilean education", en Hungarian Educational Research Journal, Volume 4, Issue 4, November 2014. 